\title{
Exploring Metropolitan Housing Price Volatility ${ }^{*}$
}

\author{
Norman Miller \\ College of Business, University of Cincinnati \\ PO Box 210195 \\ Cincinnati, OH 45221-0195 \\ Liang Peng \\ College of Business, University of Cincinnati \\ PO Box 210195 \\ Cincinnati, OH 45221-0195 \\ Email: liang.peng@uc.edu
}

Current Draft: March 26, 2004

\begin{abstract}
This paper uses MSA level data and a panel VAR model to analyze the dynamic determination and impact of the volatility of single-family home value appreciation. We find that the volatility can be magnified by an exogenous increase in the home appreciation rate, responds to changes in the population growth rate, and is serially correlated. Moreover, an exogenous increase in the volatility increases the home appreciation rate, reduces personal income growth rate and affects population growth rate. Our analysis also provides strong evidence of heterogeneity of the MSA housing markets.
\end{abstract}

JEL classification: C52, G10, R21, R31

Key words: home value appreciation, housing price volatility, urban economy, panel VAR

\footnotetext{
* We thank John Clapp, Lawrence Souza, and referees for helpful discussions. Financial aid from the Real Estate Research Institute is greatly appreciated. All errors are ours alone.
} 


\section{Exploring Metropolitan Housing Price Volatility I. Introduction}

The housing market plays an important role in the economy. First, the market per se is a tremendous component of the economy. The total value of owner occupied housing has exceeded 13 trillion dollars by the start of 2003 according to the Federal Reserve, and is comparable to the total value of the stock market, the gross domestic product, and the commercial bank assets in the same period. Therefore, the risk of the housing market is among the largest personal economic risks faced by individuals, as Shiller (1998) argues. A house is not only a dwelling but also a significant portion of the wealth of its owner. For example, middle-class American families have more than half their assets in the form of housing, as shown by Campbell and Cocco (2003). At the same time housing as an investment differs from stocks and bonds in terms of return, risk, and liquidity. The effects of housing on savings and portfolio choices are extremely important questions drawing great attention from economists. ${ }^{1}$ Particularly, since 1998 through early 2003 the stock market has proven very perilous with most investors losing substantial wealth, "Americans now appear to be treating the purchase of residential real estate as the investment of choice during times of economic uncertainty." ${ }^{2}$ Therefore, understanding the source of the housing market price volatility has great individual portfolio implications. Furthermore, the housing market affects the economy through not only wealth effects (e.g. Case et al., 2001) but also through influences on other markets such as the mortgage market, mortgage insurance and mortgage backed bonds, as well as consumer durables. Consequently, the variations in the housing market are important to key components of the overall economy and the welfare of the society.

Despite the importance of the housing market, we have found surprisingly little in the literature on the sources and impacts of the volatility of housing markets, particularly at the metropolitan statistical area (MSA) level. Among a few papers that aim to study the housing price volatility, Dolde and Tirtiroglu (1997) use data sets for towns in

\footnotetext{
${ }^{1}$ See Bond et al. (2003), Campbell and Cocco (2003), Capozza et al. (1997), Cocco (2001), Davidoff (2002), Flavin and Yamashita (2002), Fratantoni (2001), Goetzmann (1993), Goetzmann and Ibbotson (1990), Gu (2002), Hu (2001), Kullmann and Siegel (2003), Yao and Zhang (2001) among others.

${ }^{2}$ See Trimbath, S. and J. Montoya, 2002.
} 
Connecticut and near San Francisco from 1971 to 1994 and find evidence of time-varying volatility and positive relations between conditional variance and returns. Dolde and Tirtiroglu (2002) identify 36 volatility events in four regional housing markets from 1975 to 1993 , and find associations between these volatility events and economic conditions. Evenson (2003) uses annual data of 47 metropolitan markets from 1975 to 1999 to study the responses of housing price and stock to a shift in employment. He finds heterogeneity of housing supply elasticity that correlates to metropolitan characteristics. Capozza, Hendershott and Mack (2004) explore the dynamics of housing price mean reversion and responses to income, population and construction or supply costs for 62 metro areas from 1979 to 1995 . They find heterogeneity in terms of the price trend responses to these economic variables based on the time period and the specific MSA.

These works provide important insights; however, some fundamental questions regarding the volatility of housing market prices remain unanswered. The questions include why a housing market is more volatile in some periods than in others; why some markets are more volatile than others; how the volatility of housing market affects the economy and population changes; and how the relations between volatility and the economy depend on the MSA attributes.

To answer these questions, we use a six-equation VAR model to study the dynamic interactions between the volatility of home value appreciation and a few important economic and demographic variables, including the rate of home value appreciation, the per capita personal income growth rate, the population growth rate, the change of unemployment rate, and per capita gross metropolitan product (GMP) growth rate. We analyze the interactions in four types of MSAs that are categorized based on the extent of supply constraint and homeowners' leverage. Our analysis consists of three steps. First, we estimate a rational expectation model of home value appreciation for each category of MSAs. Second, we use unpredictable components of home value appreciation rates to estimate quarterly volatility series for each MSA. Finally, we estimate a panel VAR system consisting of the estimated volatility and other variables, and investigate the dynamic interactions among the variables, including the determinants and impact of housing volatility. Our analysis allows for time-varying expected appreciation rates for home values, and controls for different types of unobserved 
variables. Moreover, our analysis utilizes well-established econometric techniques such as GARCH and VAR models, and is computationally simple.

We uncover a few novel and important dynamic interactions between the volatility of home price appreciation and other variables. We find that, first, an exogenous increase (decrease) in the home appreciation rate magnifies (mitigates) the volatility. Second, the volatility is serially correlated: an exogenous increase (decrease) in the volatility magnifies (mitigates) the volatility level in subsequent periods. Third, an exogenous change in the population growth rate affects the volatility of the home value appreciation rate in a complicated way, which probably relates to the qualitative characteristics of the population change. Fourth, an exogenous increase in the volatility increases the home appreciation rate in the short turn, but reduces it in the longer turn before the effect eventually fades away. Fifth, an exogenous increase (decrease) in the volatility magnifies the volatility of the growth rate of per capita personal income, and seems to be reducing (increase) the income growth rate. Finally, an exogenous increase (decrease) in the volatility has little effect on the population growth rate in MSAs with unconstrained supplies, while it more dramatically reduces (increases) the population growth rate in MSAs with constrained housing supplies.

Our analysis also provides strong evidence of heterogeneity of the housing markets in different MSAs. For example, housing markets in MSAs with constrained housing supplies seem more sensitive to shocks and tend to respond more dramatically to them. Effects of shocks often last longer in these MSAs too. Furthermore, the effects are often cyclic in MSAs with not only constrained supplies but also high homeowners' leverage. These findings corroborate the leverage effect as well as effects of financial constraints found by Stein (1995), Genesove and Mayer (1997), Lamont and Stein (1999), and Ortlo-Magne and Rady (2001), among others, and the heterogeneous supply elasticity found by Evenson (2003).

This paper builds upon several very important literatures. First, it builds upon the literature on the efficiency of housing markets and the predictability of real estate returns (see for example Case and Shiller, 1989, 1990, Gillen et al., 2001, Gu, 2002, Cappozza et al. 2004, Miller and Sklarz, 1986, among others) because this paper incorporates a rational expectation model of home value appreciation that allows predictable expected 
appreciation rates. This paper also builds upon the literature in the return and risk characteristics of real estate (see Bond et al., 2003, Capozza et al., 2002, Capozza et al., 2003, Capozza et al 2004, Case et al., 1999, Goetzmann, 1993, among others) by investigating the sources of the volatility of housing markets. It also builds upon the literature on the relations between the housing market and economy and demographics (see for example Case and Mayer, 1996, Clapp and Giaccotto, 1994, Dispasquale and Wheaton, 1994, Leung, 2003, Quigley, 1990, and Reichert, 1990, among others) because the dynamical interrelations between the housing volatility and economic and demographic variables are studied. Furthermore, this paper has implications for mortgage default and mortgage and portfolio choices of households (see, e. g. Campbell and Cocco, 2003, Capozza et al., 1997, Yao and Zhang, 2001) due to the close relation between mortgage markets and housing markets. Finally, this paper has implications for those seeking to develop derivatives for housing market prices, including home equity insurance and futures or options of real estate (see for example Case et al., 1993, Case and Shiller, 2000, Goetzmann et al., 2003, Miller and Sklarz, 1988, among others) because the pricing of the real estate derivatives closely relates to volatility.

The paper proceeds as follows. With the next section we discuss the data. After that, we discuss the estimation of volatility series. Section 4 discusses the VAR model and presents the empirical results. Section 5 concludes.

\section{Data}

This paper uses a large panel data set which comprehensively describes the single family housing markets of the United States at the MSA level. The data comprise quarterly transaction-based price indices for single family homes, per capita personal income, population, unemployment rate, and per capita GMP for 277 MSAs from the third quarter of 1990 to the second quarter of 2002. The home price indices are provided by the Office of Federal Housing Enterprise Oversight (OFEHO); the personal income data are provided by BEA; the population data are provided by $\mathrm{BOC}$; and the unemployment and GMP data are provided by BLS. Data except the OFEHO indices are compiled by Economcy.com. To our knowledge, our data set is among the largest data sets, in terms of the number of MSAs covered, that are ever used in empirical research in urban economics and real estate economics. 
We use MSA level data because, in terms of analyzing the volatility of home value appreciation rate, MSA data are superior to aggregate national data. First, American families do not own nationally diversified houses. They own houses in specific areas and thus are subject to the volatility at the MSA level if not more specific submarkets within these areas. Besides, housing markets are not homogenous across metropolises. Therefore, aggregating data at the national level may disguise the true volatility at the local level that homeowners actually face and care. Second, MSA data provide many more observations than national data. More observations often improve the efficiency of estimation and lead to more reliable results. Third, MSA data provide rich temporal and cross-sectional variations. The variations are extremely valuable because they effectively mitigate the multi-collinearity of variables that is challenging for time series analysis and thus help identify parameters in our model.

Some important characteristics of the variables are captured in Figures 1, 2, and 3. Figure 1 shows the histograms of the arithmetic averages of quarterly home value appreciation rates, per capita personal income growth rates, population growth rates, unemployment rates, and per capita GMP growth rates for all MSAs. Figure 2 shows the histograms of the standard deviations of these series, and Figure 3 shows the histograms of the first order autoregressive coefficients of these series. The figures reveal that MSAs differ from each other in many aspects.

We use the following notations throughout this paper. For metropolis $i$ in period $t$, we denote the home price index level by $H P_{i, t}$, the per capita personal income by $P I_{i, t}$, the total population by $P O_{i, t}$, the unemployment rate by $U R_{i, t}$, the per capita gross metropolitan product by $G M P_{i, t}$. We use lower cases to represent the logged gross returns, for example $h p_{i, t}=\log \left(H P_{i, t} / H P_{i, t-1}\right)$.

\section{Estimating MSA Volatility Series}

In the first step of our analysis, we estimate a model in which market participants form rational expectations of future home value appreciation rates using all available information. We assume that all market participants are rational. In equilibrium, all participants adopt their optimal strategies, and rationally forecast the future appreciation 
rate given their knowledge of each other's optimal strategies and all other presently available information. Specifically, we assume that the realized appreciation rate of the representative house of metropolis $i$ in time period $t$ equals the sum of the expected appreciation rate (conditional upon the information set $I_{t-1}$ ) and an unpredictable shock that is independent across MSAs and time periods.

$$
h p_{i, t}=E\left[h p_{i, t} \mid I_{t-1}\right]+\varepsilon_{i, t}
$$

To correctly specify the rational expectation model as well as the VAR system we use later, we need to address a few complexities. The first complexity is latent variables, which include not only MSA specific time-invariant variables - such as locations and other time-invariant MSA characteristics, time-specific MSA-invariant variables - such as macroeconomic variables, but also variables that vary across both MSAs and time periods - such as industrial structures and demographic compositions. The latent variables represent information available to market participants but not included in our data set. Ignoring the latent variables may cause inconsistent estimation of the model.

We treat all MSA-specific time-invariant variables and all time-specific MSAinvariant variables as latent variables despite the fact that some variables are available. The main benefit of our approach is that we are able to use MSA-specific intercepts (MSA dummies) and time-specific intercepts (time dummies) to capture these variables, regardless their availability. Consequently, it is much less likely for our results to be contaminated by a few unavailable variables. Furthermore, consuming these variables into dummies helps conserve degrees of freedom, which is particularly valuable since our model includes a fairly large number of explanatory variables.

To control for the latent variables that change across both MSAs and time, we notice that the effects of these variables are captured by residuals of the estimation of a model that does not control for these variables. If these variables are serially correlated, a lagged residual, which captures the effects of lagged latent variables, would correlate with the contemporaneous latent variables, and thus is an effective proxy for them. Empirically, we first estimate a model without controlling for these latent variables. We find that the lagged residual has significant predicting power of the future home appreciation rate, which is consistent with our conjecture that the lagged residual 
correlates with the latent variables. Therefore, we include the lagged residual as an additional explanatory variable to control for the third type of latent variables.

Another complexity is the heterogeneity of housing markets across MSAs, which is documented by the literature. For example, among others, Genesove and Mayer (1997) use sales data to show that seller reservation prices are affected by the loan-to-value ratio. Lamont and Stein (1999) find a relationship between homeowner borrowing patterns - the loan-to-value ratio particularly - and house price dynamics at the city level. Evenson (2003) also finds heterogeneous housing supply elasticity that can be explained with MSA characteristics. Apparently, the heterogeneity of housing markets substantiates the possibility of MSA-variant parameters in the rational expectation model and the VAR system. An approach to address the heterogeneity is to conduct our analysis for each individual MSA, which, however, costs a large number of degrees of freedom. An alternative approach is to pool all MSAs together, which, however, gains efficiency of estimation at the cost of mis-specification of the model.

Realizing the trade off between efficiency and consistency, we conduct our analysis separately in four groups of MSAs, which are categorized based on the population level and the average bankruptcy rate. The cutoff point of population is 0.5 million, and the cutoff point of bankruptcy rate is 3.7 people per 1000 people. We choose the cutoff points so that each category has roughly the same number of MSAs. We use the population as a proxy for the supply constraint, and use the average bankruptcy rate as a proxy for homeowner leverage. ${ }^{3}$ The four types of MSAs, therefore, are those with constrained supplies and high homeowners' leverage, those with constrained supplies and low homeowners' leverage, those with unconstrained supplies and high homeowners' leverage, those with unconstrained supplies and low homeowners' leverage. "Constrained" and "unconstrained", as well as "high" and "low" leverage, are apparently relatively defined, and we use these terms just to differentiate the four types of MSAs. On one hand, our approach accommodates possible heterogeneity of housing markets that relates to homeowners' leverage and supply constraints. On the other hand, the rational expectation model can be estimated more efficiently due to a large number of

\footnotetext{
${ }^{3}$ Higher population areas are also more likely to have increased land use regulations that act as supply constraints (See, e.g., Malpezzi, 1996).
} 
observations in each category of MSAs. Figure 4 plot the scatter points of MSAs as well as the cutoff lines that separate the four categories of MSAs.

The third complexity is the heterogeneity of housing market across different economic phases, say growth versus recessions. For example, consider a housing market with a downward-sloping demand curve and a vertical supply curve. When real estate developers forecast an upward shift of the demand curve (e.g. caused by a large immigration or increasing personal income), they may optimally choose to increase housing stock by constructing new houses, which will shift the supply curve to the right. As a result of the simultaneous shifting of the demand curve and the supply curve, the house prices remain relatively stable, so the appreciation rate may be mild. On the other hand, when the market forecasts a downward shift of the demand curve with the same magnitude; little can be done to shift the supply curve to the left. Consequently, the sticky supply and decreasing demand will push down house prices, and the appreciation rate may be significantly negative. Therefore, house prices may increase modestly but drop dramatically caused by shocks with the same magnitude but different directions. To accommodate possible asymmetries of housing equilibrium in different economic phases, we allow positive and negative changes of explanatory variables to have different impact upon the expected appreciation rate.

As a result, the specification of the rational expectation model is as follows.

$$
\begin{aligned}
h p_{i, t}= & \alpha_{i}+\alpha_{t-1}+\sum_{l=1}^{4} \beta_{l}^{h p} h p_{i, t-l}+\sum_{l=1}^{4} \beta_{l}^{p i} p i_{i, t-l}^{+}+\sum_{l=1}^{4} \gamma_{l}^{p i} p i_{i, t-l}^{-} \\
& +\sum_{l=1}^{4} \beta_{l}^{p o} p o_{i, t-l}^{+}+\sum_{l=1}^{4} \gamma_{l}^{p o} p o_{i, t-l}^{-}+\sum_{l=1}^{4} \beta_{l}^{u r} u r_{i, t-l}^{+}+\sum_{l=1}^{4} \gamma_{l}^{u r} u r_{i, t-l}^{-} \\
& +\sum_{l=1}^{4} \beta_{l}^{g m p} g m p_{i, t-l}^{+}+\sum_{l=1}^{4} \gamma_{l}^{g m p} g m p_{i, t-l}^{-}+\beta_{\varepsilon} \hat{\varepsilon}_{i, t-1}+\varepsilon_{i, t} .
\end{aligned}
$$

For any variable $x_{i, t}$,

$$
x_{i, t}^{+}=\left\{\begin{array}{cc}
x_{i, t} & x_{i, t} \geq 0 \\
0 & x_{i, t}<0
\end{array} \text {, and } x_{i, t}^{-}=\left\{\begin{array}{cc}
0 & x_{i, t} \geq 0 \\
x_{i, t} & x_{i, t}<0
\end{array}\right.\right.
$$

For example, $p i_{i, t-1}^{+}$equals $p i_{i, t-1}$ if $p i_{i, t-1} \geq 0$, and 0 if $p i_{i, t-1}<0$.

Four points are worth noting. First, equation (2) includes two intercepts that capture two types of unobserved variables. The first is the individual time-invariant 
intercept, $\alpha_{i}$, which captures unobserved MSA attributes that remain constant through time but vary across MSAs. The second is the period individual-invariant intercept, $\alpha_{t-1}$, which captures all unobserved political, social, and economic variables that are the same across MSAs in period $t-1$. Second, equation (2) allows positive and negative changes of explanatory variables to have asymmetric impact upon the expected appreciation rate, so it accommodates potential asymmetries in the market equilibrium. Third, equation (2) includes four lags of each explanatory variable, which are used to capture possible seasonality. Finally, equation (2) includes the lagged residual from estimating the model that does not control for latent variables that change across both MSAs and time periods.

To identify the rational expectation model as described by equation (2), we assume $\sum_{t=1}^{T-1} \alpha_{t}=0$, which is a technique assumption and does not affect the estimation of coefficients. To estimate (2), we conduct two within transformations, within each metropolis and each time period, to eliminate the individual and period intercepts, which is equivalent to pre-multiplying (2) using the following transformation matrix,

$$
Q=I_{N T}-I_{N} \otimes \frac{1}{T} e e^{\prime}-\frac{1}{N} e_{N} e_{N}^{\prime} \otimes I_{T}+\frac{1}{N T} J,
$$

where $N$ is the number of metropolises, $T$ denotes the total periods in our sample, $I_{N T}$ denotes the $N T$ by $N T$ identity matrix, $e$ is a $T \times 1$ matrix of ones, $e_{N}$ is a $N \times 1$ matrix of ones, and $J$ is a $N T \times N T$ matrix of ones, and $\otimes$ denotes the Kronecker product. We estimate (2) with OLS. The OLS coefficient estimators are consistent when both $N \rightarrow \infty$ and $T \rightarrow \infty$ (e.g. see Hsiao, 1986) despite the dynamic nature of the equation. However, the standard deviation and t-statistic need to be adjusted due to the within transformations.

Next, we construct the unpredictable component of the appreciation rate $\varepsilon_{i, t}$. Define $e_{i, t}$ as the residual of the within regression. 


$$
\begin{aligned}
e_{i, t}= & h p_{i, t}-\sum_{l=1}^{4} \hat{\beta}_{l}^{h p} h p_{i, t-l}-\sum_{l=1}^{4} \hat{\beta}_{l}^{p i} p i_{i, t-l}^{+}-\sum_{l=1}^{4} \hat{\gamma}_{l}^{p i} p i_{i, t-l}^{-} \\
& -\sum_{l=1}^{4} \hat{\beta}_{l}^{p o} p o_{i, t-l}^{+}-\sum_{l=1}^{4} \hat{\gamma}_{l}^{p o} p o_{i, t-l}^{-}-\sum_{l=1}^{4} \hat{\beta}_{l}^{u r} u r_{i, t-l}^{+}-\sum_{l=1}^{4} \hat{\gamma}_{l}^{u r} u r_{i, t-l}^{-} \\
& -\sum_{l=1}^{4} \hat{\beta}_{l}^{g m p} g m p_{i, t-l}^{+}-\sum_{l=1}^{4} \hat{\gamma}_{l}^{g m p} g m p_{i, t-l}^{-}-\hat{\beta}_{\varepsilon} \hat{\varepsilon}_{i, t-1}
\end{aligned}
$$

Apparently, $e_{i, t}$ includes not only $\varepsilon_{i, t}$ but also $\alpha_{i}$ and $\alpha_{t}$, so we need to extract $\varepsilon_{i, t}$ from $e_{i, t}$. Note $\sum_{t=1}^{T-1} \alpha_{t}=0, \alpha_{i}$ can be estimated as follows. ${ }^{4}$

$$
\hat{\alpha}_{i}=\frac{1}{T-1} \sum_{t=2}^{T} e_{i, t}
$$

We then use the residuals of the following dummy regression for the unpredictable components of the appreciation rate.

$$
e_{i, t}-\hat{\alpha}_{i}=\alpha_{t-1}+u_{i, t}
$$

In the second step of our analysis, we use series of the unpredictable appreciation component $\hat{u}_{i, t}$ obtained from (7) to estimate volatility series. We denote by $v_{t y}$ the volatility of the housing value appreciation, which is defined as the variance of the unpredictable component $\varepsilon_{i, t}, v_{l t y}=\operatorname{var}\left(\varepsilon_{i, t}\right)$. Therefore, the larger is the variance of $\varepsilon_{i, t}$, the more volatile the housing appreciation rate is. We estimate $\left\{v l t y_{i, t}\right\}$ with a GARCH $(1,1)$ model including leverage terms. GARCH models are proposed by Bollerslev (1986), and are sophisticated tool for investigating volatility (see, for example, Schwert, 1989, Pagan and Schwert, 1990, and Engle and Ng, 1993). The number of lags in the GARCH model makes no empirical difference, as $\operatorname{GARCH}(1,2)$ and $\operatorname{GARCH}(2,2)$ generate almost identical estimation of volatility. ${ }^{5}$ The estimated volatility series are used to construct a panel VAR system, which is discussed next. Figure 5 plots the histograms of the time-average volatility in the four types of MSAs.

\footnotetext{
${ }^{4}$ We lose the first period due to the within transformations.

${ }^{5}$ Regressions of volatility series estimated with different GARCH models on each other generate R2s and slopes that are close to 1 . Regression details can be provided on request.
} 


\section{Exploring the Determinants and Impact of Volatility}

Vector autoregressions are popularized by Sims's (1980) and are wildly used to describe vector time series. In the third step, we study a VAR model that includes four lags of six variables - $h p_{i, t}, v l t y_{i, t}, p i_{i, t}, p o_{i, t}, u r_{i, t}$, and $g m p_{i, t}$. We include four lags because they are long enough to capture seasonality within a year. More lags, such as eight lags, are infeasible due to collinearity of variables.

The VAR model is as follows.

$$
\begin{aligned}
{\left[\begin{array}{c}
h p_{i, t} \\
v l t y_{i, t} \\
p i_{i, t} \\
p o_{i, t} \\
u r_{i, t} \\
g m p_{i, t}
\end{array}\right]=\left[\begin{array}{c}
\alpha_{i}^{h p} \\
\alpha_{i}^{v l t y} \\
\alpha_{i}^{p i} \\
\alpha_{i}^{p o} \\
\alpha_{i}^{u r} \\
\alpha_{i}^{g m p}
\end{array}\right]+\left[\begin{array}{c}
\alpha_{t-1}^{h p} \\
\alpha_{t-1}^{v l t y} \\
\alpha_{t-1}^{p i} \\
\alpha_{t-1}^{p o} \\
\alpha_{t-1}^{u r} \\
\alpha_{t-1}^{g m p}
\end{array}\right]+A\left[\begin{array}{c}
h p_{i, t-1} \\
v l t y_{i, t-1} \\
p i_{i, t-1}^{+} \\
p o_{i, t-1}^{+} \\
u r_{i, t-1}^{+} \\
g m p_{i, t-1}^{+} \\
p i_{i, t-1}^{-} \\
p o_{i, t-1}^{-} \\
u r_{i, t-1}^{-} \\
g m p_{i, t-1}^{-}
\end{array}\right]+B\left[\begin{array}{c}
h p_{i, t-2} \\
v l t y_{i, t-2} \\
p i_{i, t-2}^{+} \\
p o_{i, t-2}^{+} \\
u r_{i, t-2}^{+} \\
g m p_{i, t-2}^{+} \\
p i_{i, t-2}^{-} \\
p o_{i, t-2}^{-} \\
u r_{i, t-2}^{-} \\
g m p_{i, t-2}^{-}
\end{array}\right] } \\
+C\left[\begin{array}{c}
h p_{i, t-3} \\
v l t y_{i, t-3} \\
p i_{i, t-3}^{+} \\
p o_{i, t-3}^{+} \\
u r_{i, t-3}^{+} \\
g m p_{i, t-3}^{+} \\
p i_{i, t-3}^{-} \\
p o_{i, t-3}^{-} \\
u r_{i, t-3}^{-} \\
g m p_{i, t-3}^{-}
\end{array}\right]+D\left[\begin{array}{c}
h p_{i, t-4} \\
v l t y_{i, t-4} \\
p i_{i, t-4}^{+} \\
p o_{i, t-4}^{+} \\
u r_{i, t-4}^{+} \\
g m p_{i, t-4}^{+} \\
p i_{i, t-4}^{-} \\
p o_{i, t-4}^{-} \\
u r_{i, t-4}^{-} \\
g m p_{i, t-4}^{-}
\end{array}\right]+E\left[\begin{array}{l}
\hat{u}_{i, t-1}^{h p} \\
\hat{u}_{i, t-1}^{v l t y} \\
\hat{u}_{i, t-1}^{p i} \\
\hat{u}_{i, t-1}^{p o} \\
\hat{u}_{i, t-1}^{u r} \\
\hat{u}_{i, t-1}^{g m p}
\end{array}\right]+U_{t}
\end{aligned}
$$

The coefficient matrixes $\mathrm{A}, \mathrm{B}, \mathrm{C}$, and $\mathrm{D}$ are 6 by 10 , and $\mathrm{E}$ is 6 by $6 . U_{t}$ is a 6 by 1 vector of error terms with zero mean and orthogonal to all explanatory variables.

Three points are worth noting in equation (8). First, we still use individual intercepts to capture time-invariant MSA attributes, and use period intercepts to capture macro factors that affect all MSAs in any given periods. Note that the relationships we 
investigate may be interpreted as relationships among real terms since the national average inflation rate has been absorbed by the period intercept. Second, we still separate positive values from negative values for per capita personal income, population, unemployment rate, and per capita GMP to accommodate possible asymmetric effects of these variables upon home value appreciation and volatility. Third, we include lagged regression residuals as proxies for latent variables that change across both time and MSAs. The regression residuals are estimated based on a model that is identical to equation (8) but does not include the regression residuals.

The estimation of the system described by equation (8) is conducted row by row, and the estimation of each row is similar to the estimation of the rational expectation model of home value appreciation. After estimating the coefficients in (8), we are able to analyze the dynamic response of the volatility to exogenous changes in other variables, as well as the dynamic responses of other variables to exogenous changes in the volatility. We focus on pairs of variables that statistically significantly affect each other. ${ }^{6}$ Particularly, we study the dynamic response of volatility to exogenous changes in the home price appreciation rate, volatility itself, and population growth rate, respectively, as well as the effects of an exogenous change of volatility on the home price appreciation rate, per capita personal income growth rate, and population growth rate.

To construct the impulse response functions, we follow the convention (e.g. Hamilton, 1994) and let all lagged variables and intercepts to be 0 , and introduce a transitory shock on a particular noise term but not others. Since the VAR system is a log linear system, a noise that equals $\log (1.1)$ implies that the corresponding variable has an unexpected increase of $10 \%$. A noise that equals $\log (0.9)$ implies that the variable has an unexpected decrease of $10 \%$. We let all noise terms be 0 after the period when the shock takes place. Consequently, the shock is transitory. The values of the six endogenous variables after the shock takes place are calculated by plugging into the VAR system the estimated coefficients, the shock, the noise terms, and the initial values of the lagged variables, which are all 0 . We then plot the time series of the exponential changes of the $\log$ variable we want to analyze as the dynamic response of the variable to the transitory

\footnotetext{
${ }^{6}$ We say variable A significantly affects variable B if at least one lag of A is statistically significant as an explanatory variable in the determination of B.
} 
shock. Note that if the exponential change is 1 , the value of the (not-logged) variable is the same with the value when there were no shock; if the exponential change is $1+x$, the value of the (not-logged) variable is $1+x$ times of the value when there were no shock.

The first important finding is that an exogenous increase in the home appreciation rate magnifies the volatility. As figure 6 shows, for all four categories of MSAs, the volatility starts to increase immediately after the shock, reaches its peak about a year after the shock, and then gradually returns to its normal level. At the same time, we observe heterogeneity in the pattern of the volatility changes. For example, the volatility seems to respond more promptly in MSAs with constrained supplies, which seems reasonable because it would be more difficult for these MSAs to adjust their housing supplies quickly to the shock. Moreover, on the path where the volatility returns to its normal level, there seems an over-shoot in MSAs with constrained supplies and high homeowners' leverage. In fact, the volatility once drops below the normal level significantly before it gradually moves up again and returns to the normal level.

We also notice that an exogenous decrease in the home appreciation rate mitigate the volatility. However, there seem differences. For an exogenous increase of the home appreciation rate, the volatility moves the most slowly back to the normal level in MSAs with unconstrained supplies and low homeowners' leverage, while for an exogenous decrease in the home appreciation rate, it is in the MSAs with constrained supplies and low homeowners' leverage that have the volatility moving the most slowly.

The second important finding is that an exogenous increase (decrease) in the volatility magnifies (mitigates) the volatility level in subsequent periods before it returns to the normal level, which is similar to the well known serially correlated volatility in the stock market. Figure 7 demonstrates the serial correlation of the volatility, and also reveals interesting distinctions between the patterns of the dynamic response in different MSAs. First, the exogenous change of the volatility fades away more slowly in MSAs with constrained supplies, and it fades away the most slowly in MSAs with constrained supplies and high homeowners' leverage. Second, the volatility appears to be cyclic in MSAs with constrained supplies and high homeowners' leverage, while it seems monotonic in other MSAs. 
The third finding is regard to the dynamic response of the volatility to an exogenous change in the population growth rate, which Figure 8 reveals. This finding is complex and intriguing because the pattern of the response differs significantly across MSAs and depends on the direction of the exogenous change in the population growth rate. For instance, an exogenous change in the population growth rate mitigates the volatility by up to $10 \%$ in MSAs with constrained supplies and low homeowners' leverage, regardless its direction (positive or negative). In MSAs with unconstrained supplies and low homeowners' leverage, an increase in the population growth rate does not affect the volatility too much, while a decrease in the population growth rate magnifies the volatility by up to $14 \%$. Moreover, in MSAs with constrained supplies and high homeowners' leverage, the change in the volatility follows a reversed U shape as the response to an exogenous increase in the population growth rate, while it demonstrates an apparent cyclic pattern after a decrease in the population growth rate.

Theory is lacking in interpreting these phenomena. Nonetheless, we conjecture that the heterogeneity of the response may capture the qualitative differences in population changes in different MSAs, such as the changes of the skill level of the labor force due to the change of population. An increase of population growth rate caused by highly skilled immigrants certainly has different consequences than an increase caused by low skilled immigrants. Though we have controlled for many unobserved variables in the VAR system, we are unable to control for these possible qualitative differences in the population changes. We leave this topic for future research.

The fourth finding is that an exogenous increase in the volatility increases the home appreciation rate in the short turn, but reduces it in the longer turn before the effect eventually fades away, which is demonstrated by Figure 9. The change in the home appreciation rate is much more dramatic in MSAs with constrained supplies. For example, the home appreciation rate increases by almost 5\% when it reaches the peak, and drops below the normal level by about $4 \%$ when it reaches the bottom. The increase of the home appreciation rate immediately after a volatility shock is consistent with the notion that homeowners demand a higher risk premium to compensate for the higher volatility. The decrease of the home appreciation rate is accompanied by the decrease of the volatility, which is also sensible because a transitory volatility shock should not 
permanently increase the home appreciation rate. However, it is very interesting to observe the overshooting of the home appreciation rate when it goes down: the home appreciation rate drops below the normal level significantly before it eventually returns to the normal level. The overshooting is drastic in MSAs with constrained supplies, which may suggest that markets with constrained supplies are more vulnerable to volatility shocks. It is worth noting that the seemingly messy changes of the home appreciation rate after the volatility shock may be consistent with Figure 7: the home appreciation rate is more volatile after the shock.

The fifth finding is that an exogenous increase (decrease) in the volatility magnifies the volatility of the growth rate of per capita personal income, and may reduce (increase) the income growth rate before the effect eventually fades away, which is shown by Figure 10. Our interpretation of this phenomenon is that an increase in the volatility of the home appreciation rate may negatively affect the housing industry (e.g. some builders may go bankrupt), which has a negative externality on the local economy. Furthermore, due to the wealth effect of houses, consumption may be negative affected by the more volatile home appreciation rate, which may also hurt the local economy.

Once again, we observe significant distinctions among MSAs. First, the response of the income growth rate to the change in volatility is more drastic in MSAs with constrained supplies than in MSAs with unconstrained supplies. Second, the effect of the volatility change fades away the most slowly in MSAs with constrained supplies and high homeowners' leverage. Moreover, in these MSAs but not others, the change of the income growth rate seems cyclic.

The sixth finding is that an exogenous increase (decrease) in the volatility has little effect on the population growth rate in MSAs with unconstrained supplies, while it more dramatically reduces (increases) the population growth rate in MSAs with constrained housing supplies. However, the magnitude of the effects is modest: no more than 2\%. In addition, we observe the cyclic pattern of the response in MSAs with constrained supplies and high homeowners' leverage. 


\section{Conclusions}

This paper analyzes the determinants and impact of the volatility of home price appreciation rate. The volatility series are estimated with GARCH models using regression residuals from rational expectation models of home appreciation rates. A sixequation panel VAR system is then used to study the dynamic interactions among the volatility, the home appreciation rate, the per capita personal income growth rate, the population growth rate, the unemployment rate change, and the per capita GMP growth rate. In our analysis, we control for three types of latent variables - MSA specific timeinvariant variables, time-specific MSA-invariant variables, and variables that vary across both MSAs and time periods, and obtain a convincing picture of the dynamics of the remaining relationships among the variables.

Our analysis provides novel and important results. First, an exogenous increase (decrease) in the home appreciation rate magnifies (mitigates) the volatility. Second, the

volatility is serially correlated: an exogenous increase (decrease) in the volatility magnifies (mitigates) the volatility level in subsequent periods. Third, an exogenous change in the population growth rate has complicated effects on the volatility of the home value appreciation rate, probably depending on the qualitative characteristics of the change. Fourth, an exogenous increase in the volatility increases the home appreciation rate in the short turn, but reduces it in the longer turn before the effect eventually fades away. Fifth, an exogenous increase (decrease) in the volatility magnifies the volatility of the growth rate of per capita personal income, and seems to be reducing (increase) the income growth rate. Finally, an exogenous increase (decrease) in the volatility has little effect on the population growth rate in MSAs with unconstrained supplies, while it more dramatically reduces (increases) the population growth rate in MSAs with constrained housing supplies.

Our analysis also provides strong evidence of heterogeneity of the housing market as well as the urban economy among MSAs. Housing markets in MSAs with constrained housing supplies seem more vulnerable and tend to respond more dramatically to shocks. Effects of shocks often last longer in these MSAs. Furthermore, the effects are often cyclic in MSAs with not only constrained supplies but also high homeowners' leverage. 
To our knowledge, this paper is the first to systematically analyze the determinants and impact of the volatility of home price appreciation rate at the MSA level, which is tremendously important given the significance of the housing market in the economy. We develop a novel and transparent approach that is based on well established econometric techniques such as GARCH and VAR models. Our empirical findings are novel and provide valuable insights into the dynamics of the housing market. However, challenges remain. For example, the interactions between demographic changes and the housing market dynamics need to be better understood. We leave them for future research. 


\section{References:}

Bollerslev, Tim. "Generalized Autoregressive Conditional Heteroskedasticity." Journal of Econometrics, 1986, 31, pp 307-27.

Campbell, John Y. and Cocco, Joao F. "Household Risk Management and Optimal Mortgage Choice." Quarterly Journal of Economics, 2003, 118(4) forthcoming.

Capozza, Dennis R.; Kazarian, Dick and Thomson, Thomas A. "Mortgage Default in Local Markets." Real Estate Economics, 1997, 25(4), pp. 631-55.

Capozza, Dennis R.; Hendershott, Patric H.; Mack, Charlotte and Mayer, Christopher J. "Determinants of Real House Price Dynamics." National Bureau of Economic Research Working Paper (Cambridge MA) No. 9262, October 2002.

Capozza, Dennis R.; Hendershott, Patric H. and Mack, Charlotte. "An Anatomy of Price Dynamics in Illiquid Markets: Analysis and Evidence from Local Housing Markets" Real Estate Economics, 2004, 32, pp. 1-32.

Case, Karl E.; Mayer, Christopher J. "Housing Price Dynamics within a Metropolitan Area." Regional Science and Urban Economics, 1996, 26, pp. 387-407.

Case, Karl E.; Quigley, John M. and Shiller, Robert. "Comparing Wealth Effects: The Stock Market versus the Housing Market." National Bureau of Economic Research Working Paper (Cambridge MA) No. 8606, November 2001.

Case, Karl E. and Shiller, Robert. "The Efficiency of the Market for Single Family Homes." American Economic Review, 1989, 79(1), pp. 125-37.

Case, Karl E. and Shiller, Robert. "Forecasting Prices and Excess Returns in the Housing Market.” AREUEA Journal, 1990, 18(3), pp. 253-73.

Clapp, John M. and Giaccotto, Carmelo. "The Influence of Economic Variables on Local House Price Dynamics.” Journal of Urban Economics, 1994, 36(2) pp. 161-183.

Cocco, Joao F. "Portfolio Choice in the Presence of Housing." London Business School Working Paper, 2001.

Davidoff, Thomas. "Labor Income, Housing Prices, and Homeownership." Haas School of Business, UC Berkeley Working Paper, 2002.

Dispasquale, Denise and Wheaton, William C. "Housing Market Dynamics and the Future of Housing Prices." Journal of Urban Economics, 1994, 35(1), 1-27.

Dolde, Walter and Tirtiroglue, Dogan. "Temporal and Spatial Information Diffusion in Real Estate Price Changes and Variances." Real Estate Economics, 1997, 25(4), pp. 539-65.

Dolde, Walter and Tirtiroglue, Dogan. "Housing Price Volatility Changes and Their Effects." Real Estate Economics, 2002, 30(1), pp. 41-66. 
Engle, Robert F. and Ng, Victor K. "Measuring and Testing the Impact of News on Volatility." Journal of Finance, 1993, 48(4), pp. 1749-78.

Evenson, Bengte. "Understanding House Price Volatility: Measuring and Explaining the Supply Side of Metropolitan Area Housing Markets." Illinois State University Working Paper, April 2003.

Flavin, Marjorie and Yamashita, Takashi. "Owner-Occupied Housing and the Composition of the Household Portfolio.” American Economic Review, 2002, 92, pp. 345-62.

Genesove, David and Mayer, Christopher. "Equity and Time to Sale in the Real Estate Market," American Economic Review, 1997, 87(3), pp. 255-69.

Gillen, Kevin; Thibodeau, Thomas and Wachter, Susan. "Anistrophic Autocorrelation in House Prices.” Journal of Real Estate Finance and Economics, 2001, 23(1), pp. 5-30.

Goetzmann, William N. "The Single Family Home in the Investment Portfolio." Journal of Real Estate Finance and Economics, 1993, 6(3), pp. 201-22.

Goetzmann, William N.; Caplin, Andrew; Hangen, Eric; Nalebuff, Barry; Prentice, Elisabeth; Rodkin, John; Spiegel, Matthew and Skinner, Tom. "Home Equity Insurace: A Pilot Project." Yale International Center for Finance Working Paper, July 2003.

Goetzmann, William N. and Ibbotson, Roger G. "The Performance of Real Estate as an Asset Class." Journal of Applied Corporate Finance, 1990, 3, pp. 65-76.

Goetzmann, William N. and Peng, Liang. "Estimating Indices in the Presence of Seller Reservation Prices," Yale International Center for Finance Working Paper, April 2003.

Gu, Anthony Y. “The Predictability of Home Prices." Journal of Real Estate Research, 2002, 24(3), pp. 213-34.

Hamilton, James D. Time Series Analysis. Princeton, New Jersey: Princeton University Press, 1994.

Hsiao, Cheng. Analysis of Panel Data. Cambridge, United Kingdom: Cambridge University Press, 1986.

Hu, Xiaoqing. "Portfolio Choices for Home Owners." Northwestern University Working Paper, 2001.

Kullmann, Cornelia, and Siegel, Stephan. "Real Estate and Its Role in Household Portfolio Choice." University of British Columbia Working Paper, 2003.

Leung, Charles K. Y. "Economic Growth and Increasing Housing Price." Chinese University of Hong Kong Working Paper, 2003.

Malpezzi, Stephen "House Prices, Externalities and Regulation in U.S. Metropolitan Areas". Journal of Housing Research, 7(2), 1996, pp. 209-41. 
Miller, Norman G. and Sklarz, Michael. "It's Time for Some Options in Real Estate." Real Estate Securities, 1988, 9, Nov. 1.

Miller, Norman G. and Sklarz, Michael. "Leading Indicators of Housing Market Price Trends," Journal of Real Estate Research, 1 (1) Fall, 1986.

Ortalo-Magné, François and Rady, Sven. "Housing Market Dynamics: On the Contribution of Income Shocks and Credit Constraints." CESifo Working Paper Series No. 470

Pagan, Adrian R. and Schwert, William G. "Alternative Models for Conditional Stock Volatility.” Journal of Econometrics, 1990, 45(1-2), pp. 267-90.

Quigley, John M. "Real Estate Prices and Economic Cycles." International Real Estate Review, 1999, 20(1): pp.1-20.

Reichert, Alan K. "The Impact of Interest Rates, Income, and Employment upon Regional Housing Prices.” Journal of Real Estate Finance and Economics, 1990, 3(4), pp. 373-91.

Rose, Louis A. "Urban Land Supply: Natural and Contrived Restrictions." Journal of Urban Economics, 1989, 25(3), pp. 325-45.

Schwert, William G. "Why Does Stock Market Volatility Change Over Time?" Journal of Finance, 1989, 44, pp. 1115-53.

Shiller, Robert. Macro Markets: Creating Institutions for Managing Society's Largest Economic Risks. New York, NY: Oxford University Press, 1998.

Sims, Christopher A. "Macroeconomics and Reality." Econometrica, 1980, 48, pp. 1-48.

Stein, Jeremy C. "Prices and Trading Volume in the Housing Market: A Model with DownPayment Effects," Quarterly Journal of Economics, 1995, 110(2), pp. 379-406.

Trimbath, Susanne. and Montoya, Juan. "A New Kind of Gold? Investment in Housing in Times of Economic Uncertainty.” Milken Institute Policy Brief, 30, June, 2002.

Yao, Rui and Zhang, Harold H. "Optimal Consumption and Portfolio Choices with Risky Housing and Stochastic Labor Income." University of North Carolina at Chapel Hill Working Paper, 2001. 


\section{Figure 1}

This figure shows the histograms of the arithmetic averages of quarterly home value appreciation rates, per capita personal income growth rates, population growth rates, unemployment rates, and per capita GMP growth rates for MSAs.
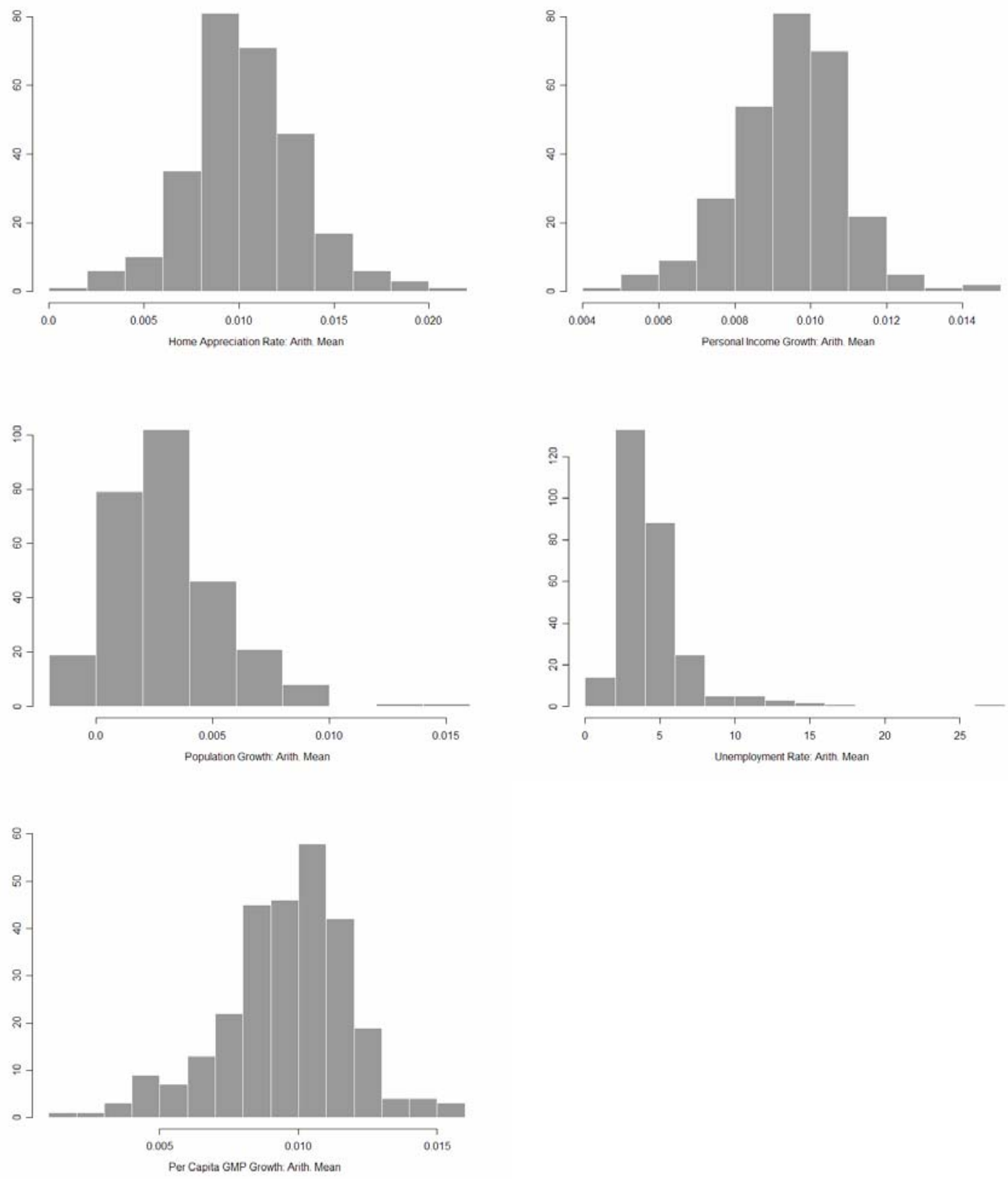


\section{Figure 2}

This figure shows the histograms of the standard deviations of quarterly home value appreciation rates, per capita personal income growth rates, population growth rates, unemployment rates, and per capita GMP growth rates for MSAs.



\section{Figure 3}

This figure shows the histograms of the first order autoregressive coefficients of quarterly home value appreciation rate, per capita personal income growth rate, population growth rate, unemployment rate, and per capita GMP growth rate for MSAs.
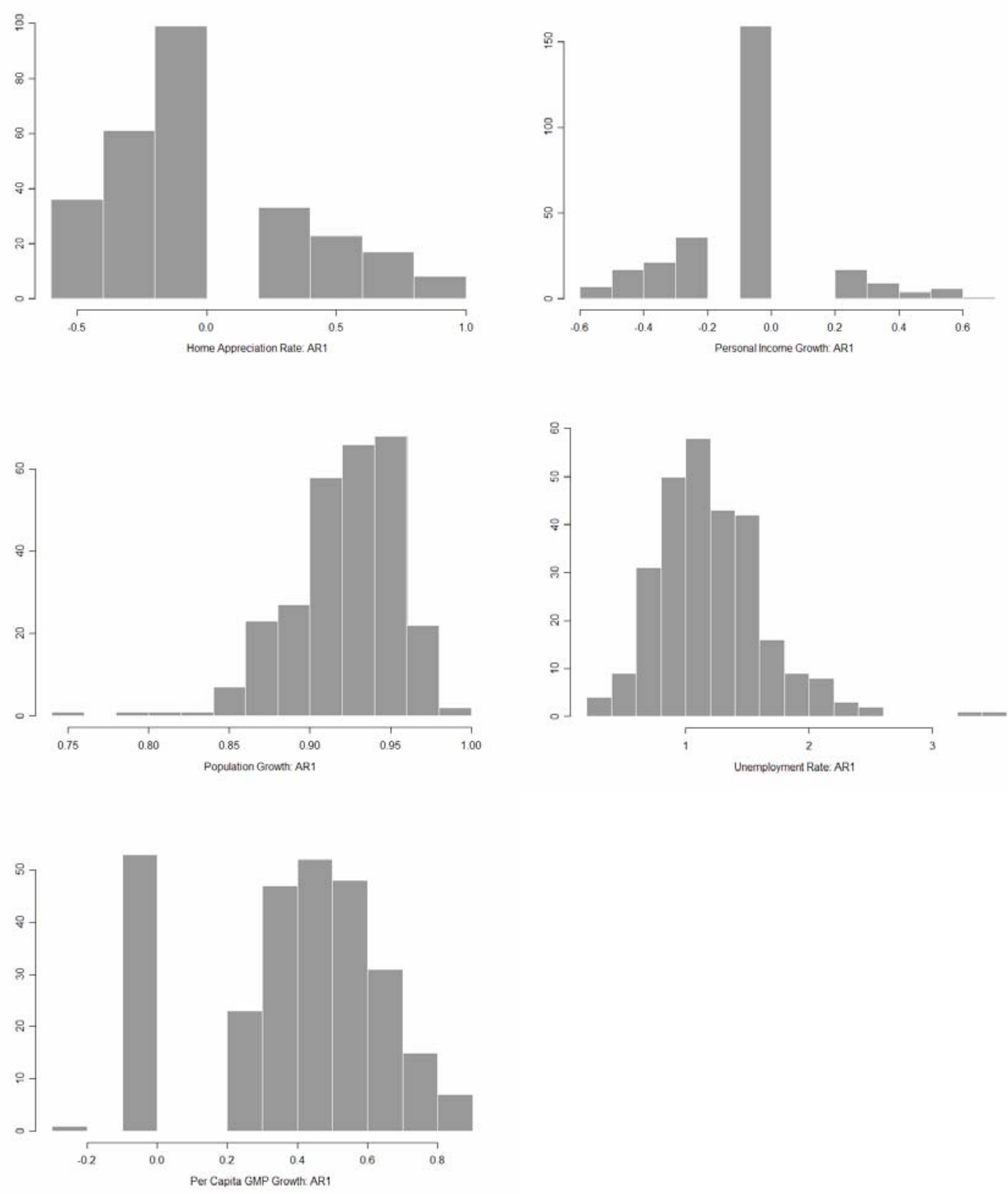


\section{Figure 4}

This figure shows scatter points of MSAs plotted according to their population (in 1000 people) and personal bankruptcy rate (per 1000 people). It also shows the four categories of MSAs - starting left-up and following the clockwise order - Constrained supply and low leverage, constrained supply and high leverage, unconstrained supply and high leverage, and unconstrained supply and low leverage.

\section{Population and Personal Bankruptcy Rates}

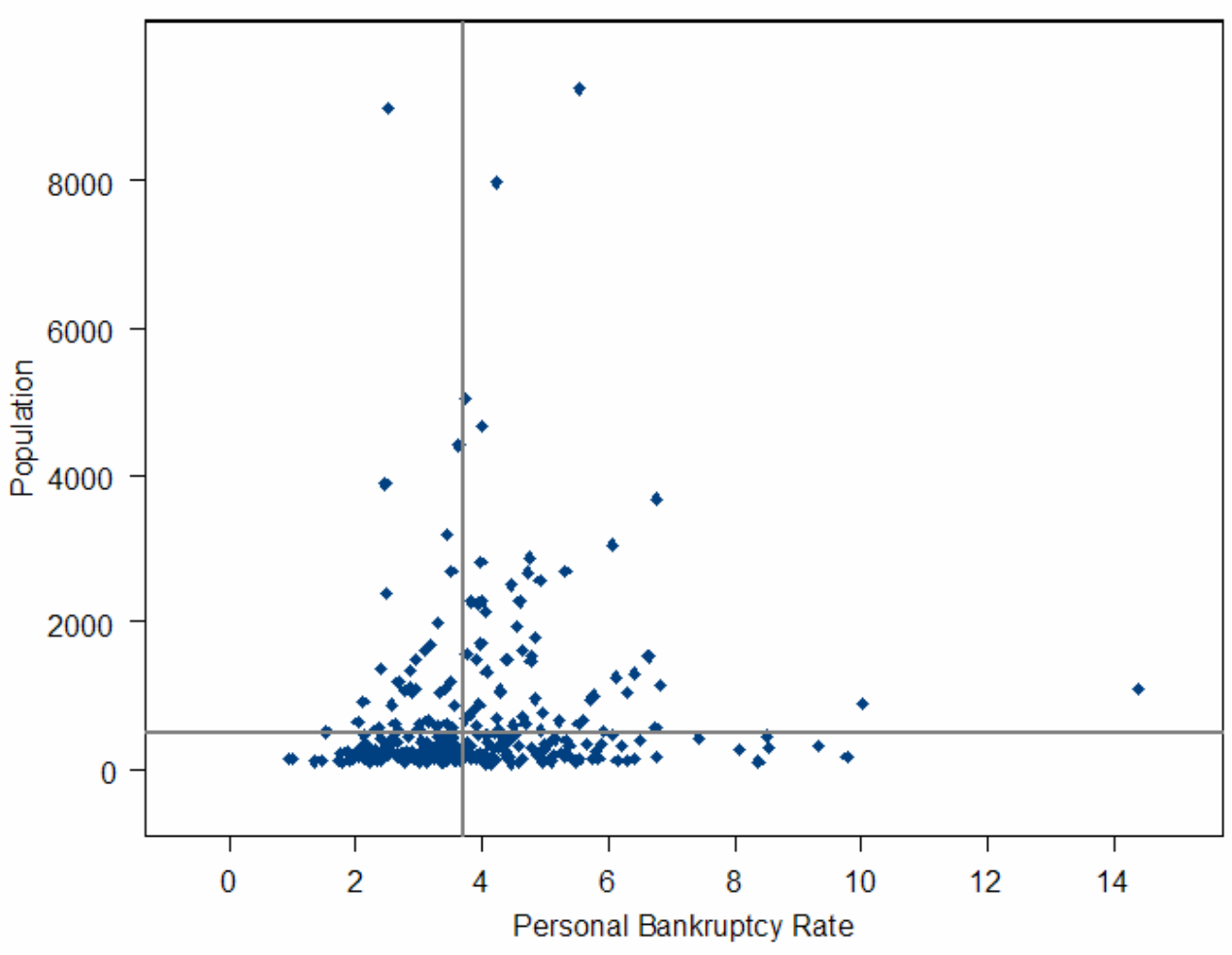




\section{Figure 5}

This figure shows the histograms of the time-average volatilities of home value appreciation rates for four types of MSAs: those with unconstrained (constrained) supplies and high (low) homeowners' leverage.
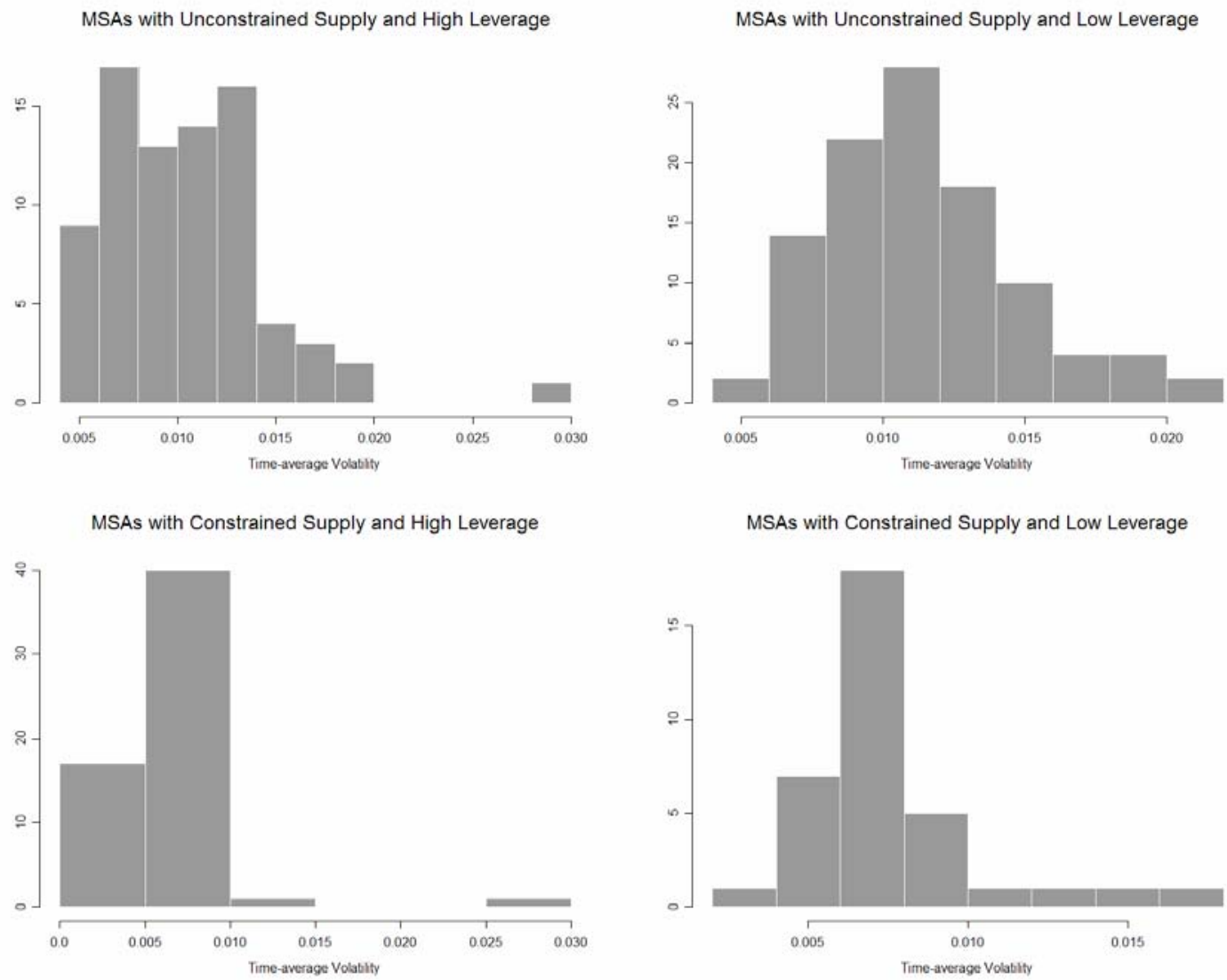


\section{Figure 6}

This figure shows the dynamic response of the house price appreciation volatility to a transitory $10 \%$ change and a transitory $-10 \%$ change in the house price appreciation rate.

Response of Volatility to A Positive Home Appreciation Change

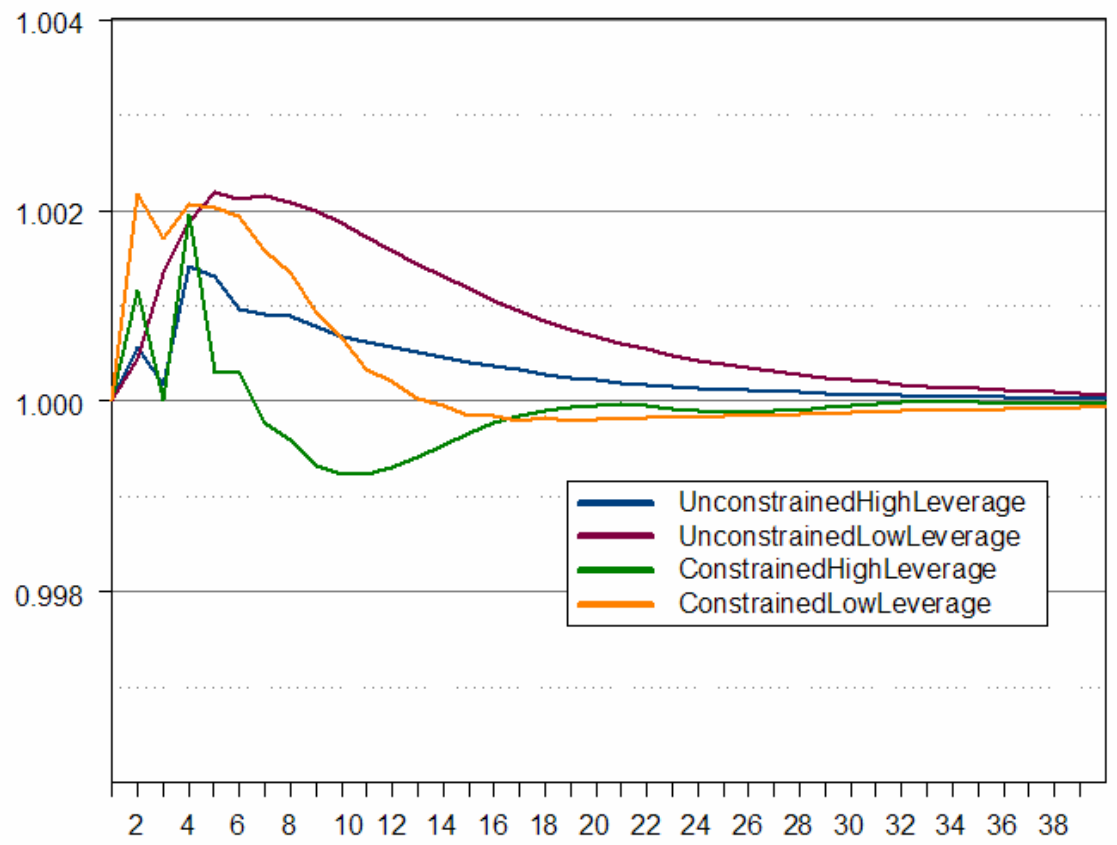

Response of Volatility to A Negative Home Appreciation Change

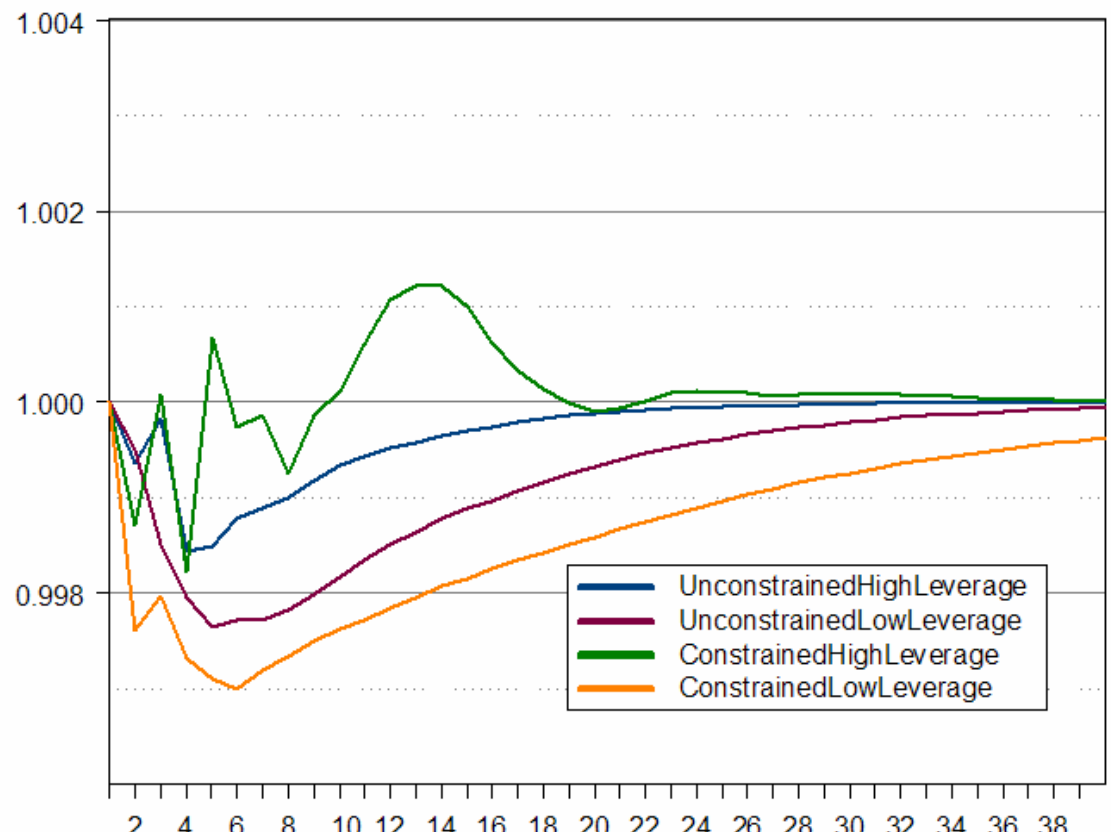

$\begin{array}{lllllllllllllllllll}2 & 4 & 6 & 8 & 10 & 12 & 14 & 16 & 18 & 20 & 22 & 24 & 26 & 28 & 30 & 32 & 34 & 36 & 38\end{array}$ 


\section{Figure 7}

This figure shows the dynamic response of the house price appreciation volatility to a transitory $10 \%$ change and a transitory $-10 \%$ change in the volatility.

\section{Response of Volatility to A Positive Vloatility Change}

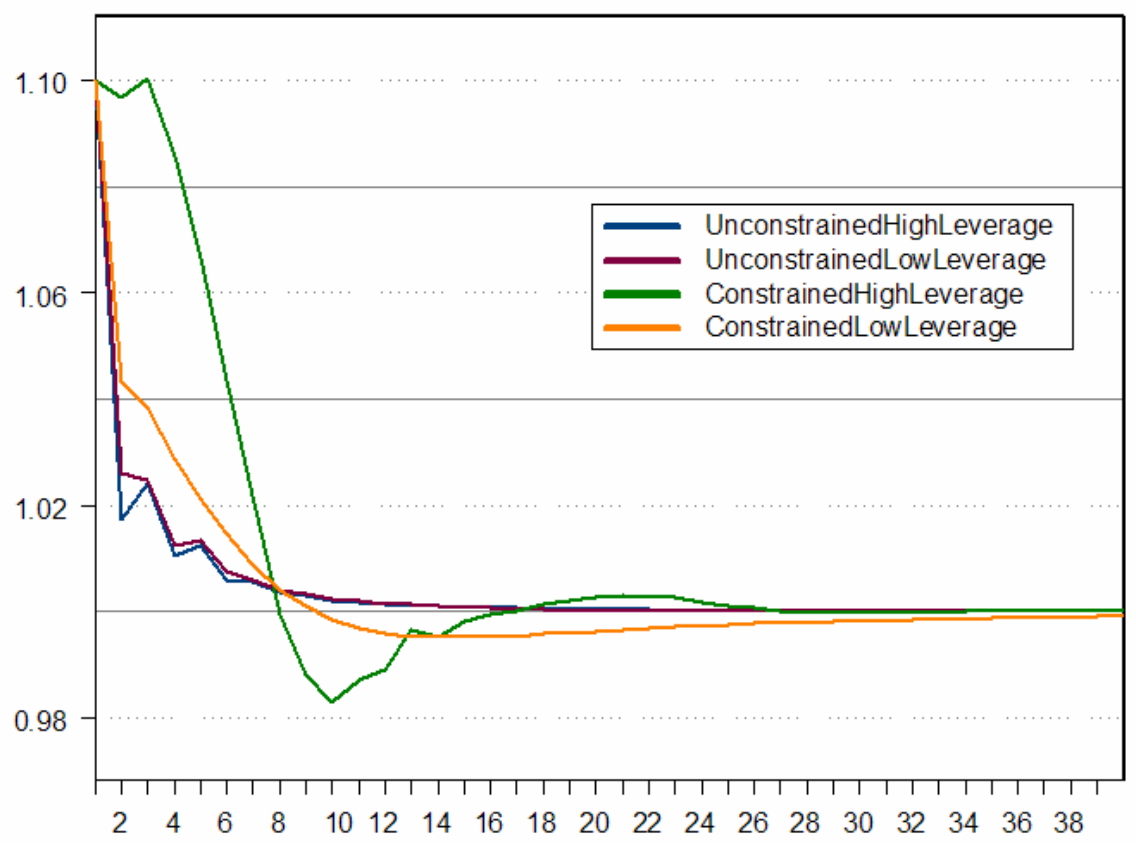

\section{Response of Volatility to A Negative Vloatility Change}

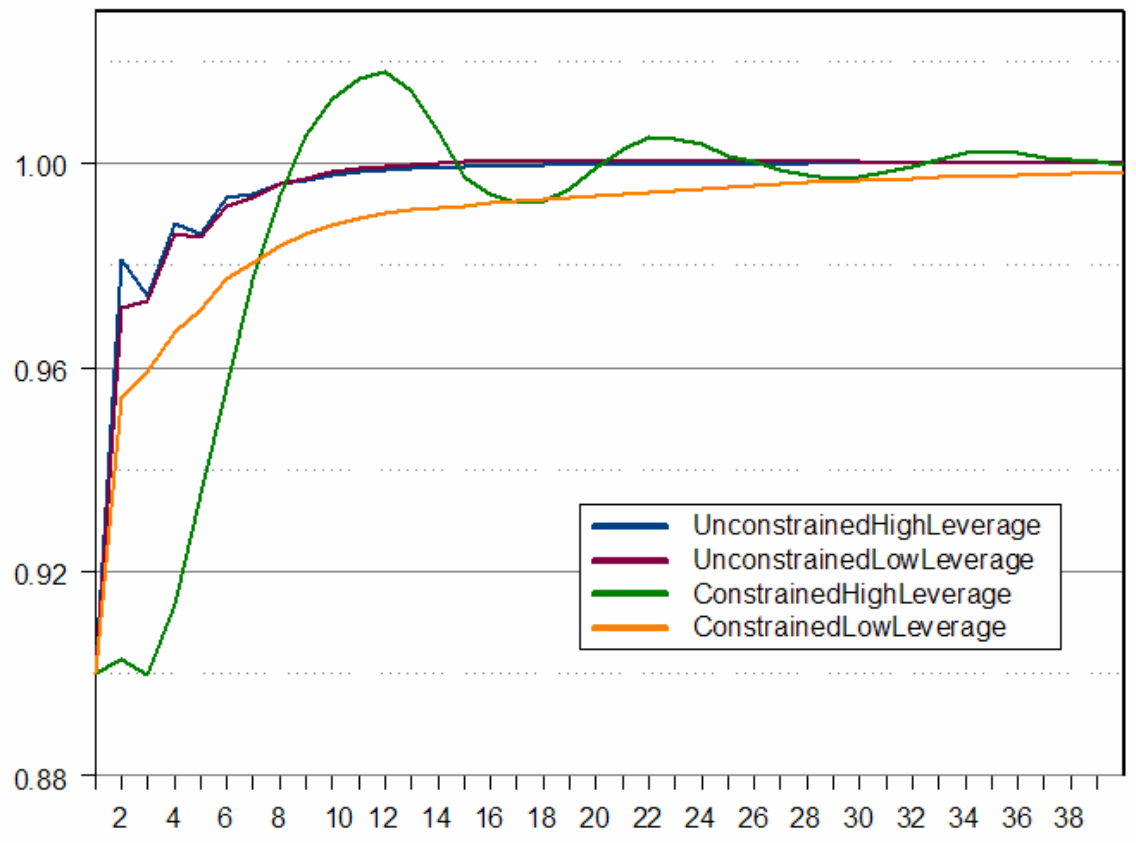




\section{Figure 8}

This figure shows the dynamic response of the house price appreciation volatility to a transitory $10 \%$ change and a transitory $-10 \%$ change in the population growth rate.

\section{Response of Volatility to An Increase in Population Growth}

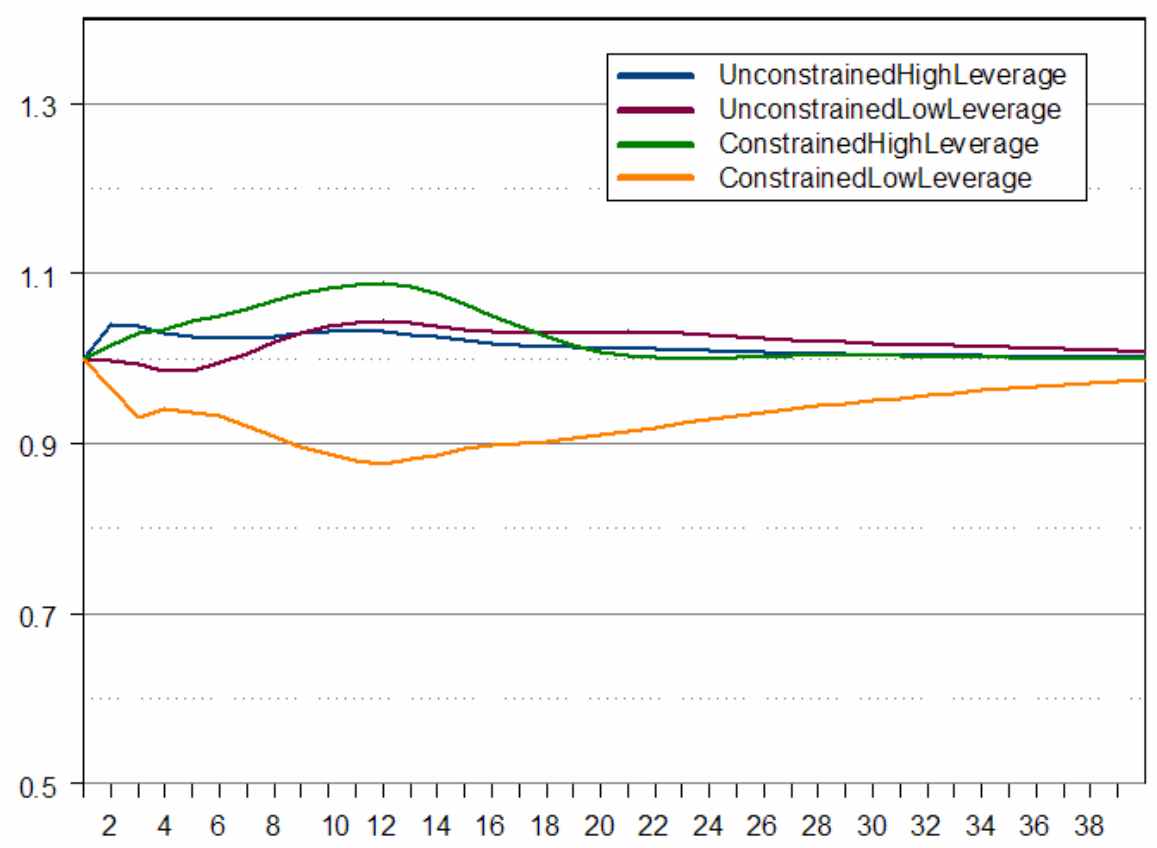

\section{Response of Volatility to A Decrease in Population Growth}

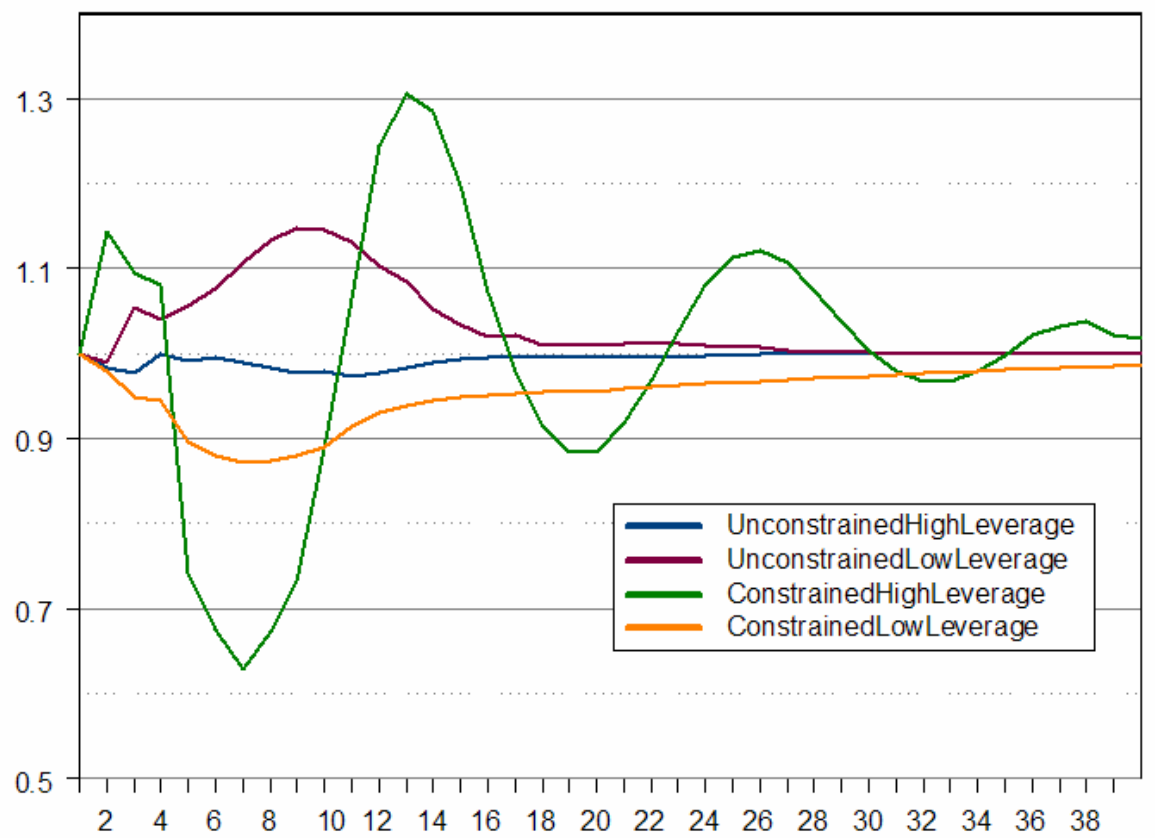




\section{Figure 9}

This figure shows the dynamic response of the house price appreciation rate to a transitory $10 \%$ change and a transitory $-10 \%$ change in the volatility.

Response of Home Appreciation to A Positive Volatility Change

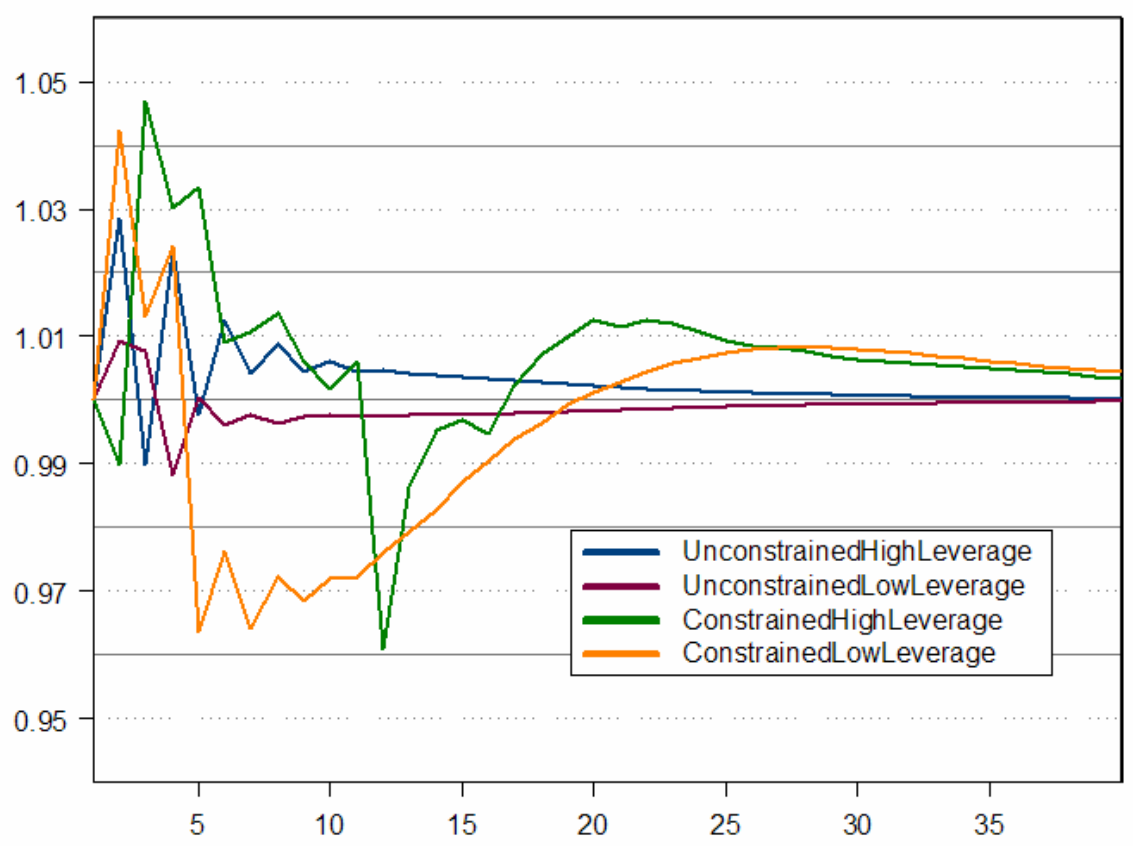

Response of Home Appreciation to A Negative Volatility Change

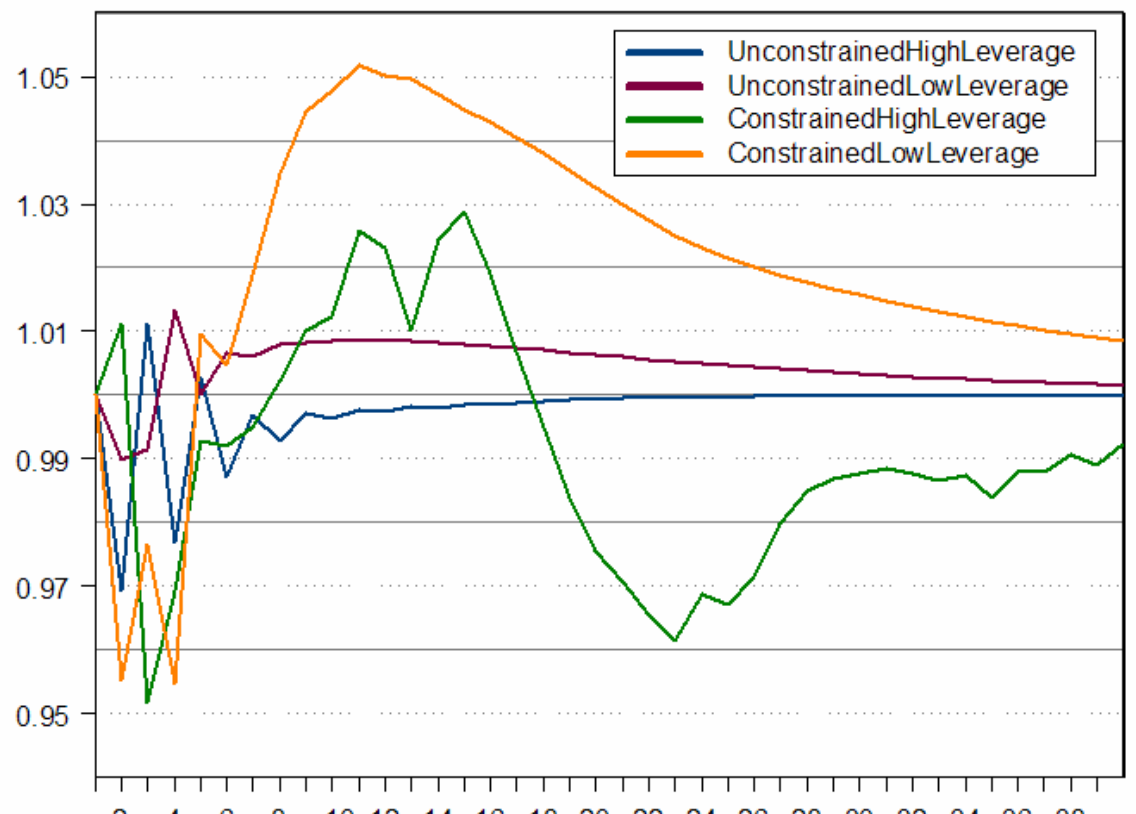

$\begin{array}{lllllllllllllllllll}2 & 4 & 6 & 8 & 10 & 12 & 14 & 16 & 18 & 20 & 22 & 24 & 26 & 28 & 30 & 32 & 34 & 36 & 38\end{array}$ 


\section{Figure 10}

This figure shows the dynamic response of the growth rate of per capita personal income to a transitory $10 \%$ change and a transitory $-10 \%$ change in the volatility.

\section{Response of Personal Income to A Positive Volatility Change}

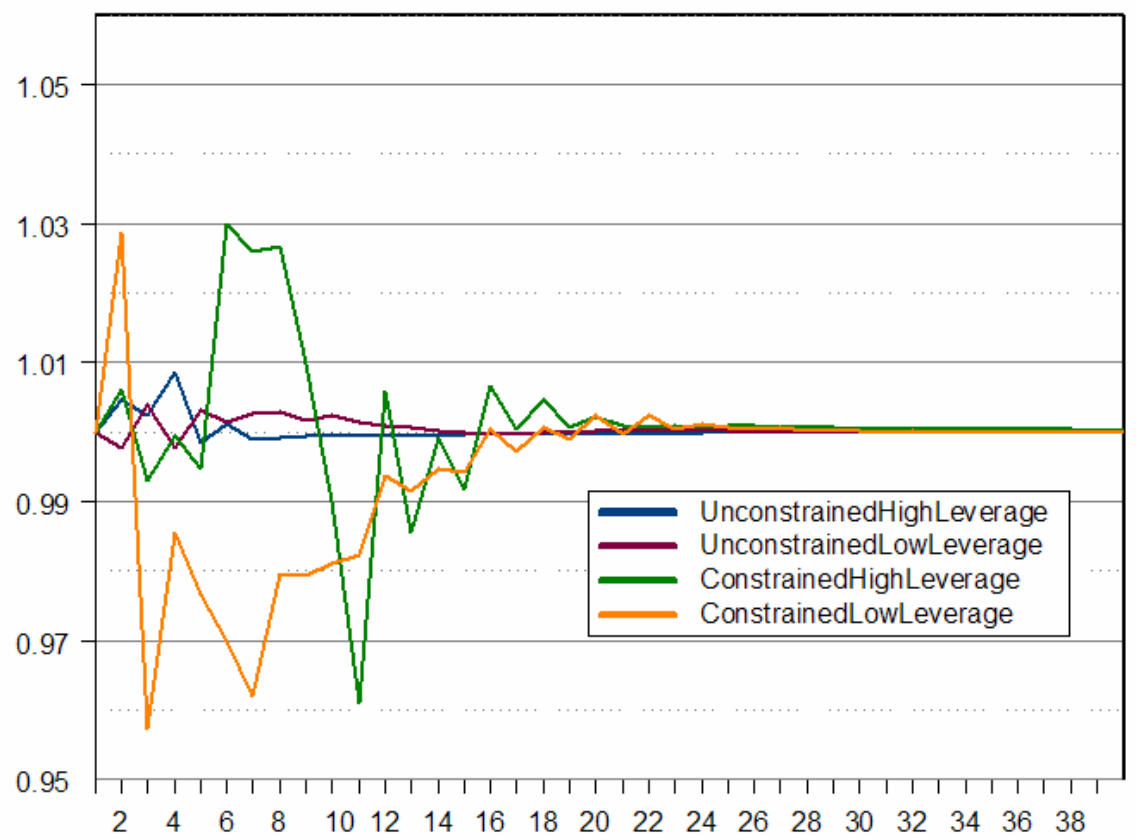

\section{Response of Personal Income to A Negative Volatility Change}

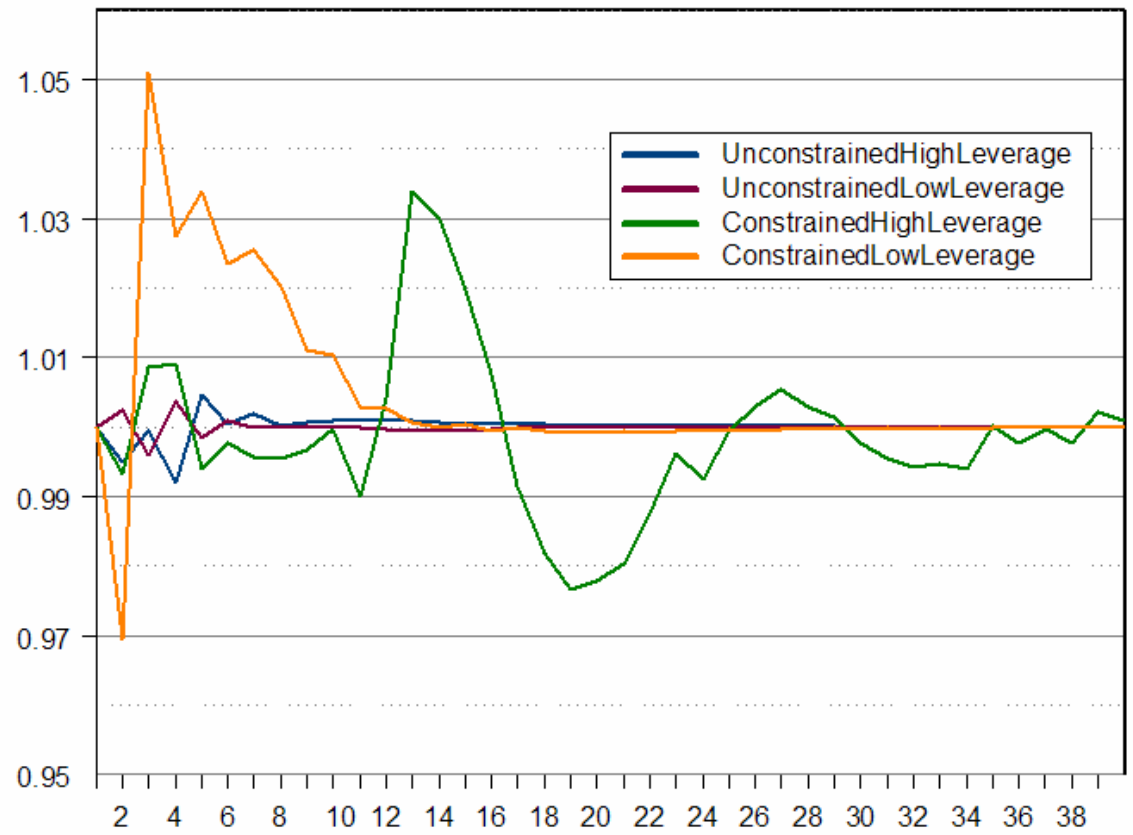




\section{Figure 11}

This figure shows the dynamic response of the population growth rate to a transitory $10 \%$ change and a transitory $-10 \%$ change in the volatility.

\section{Response of Population Growth to A Positive Volatility Change}

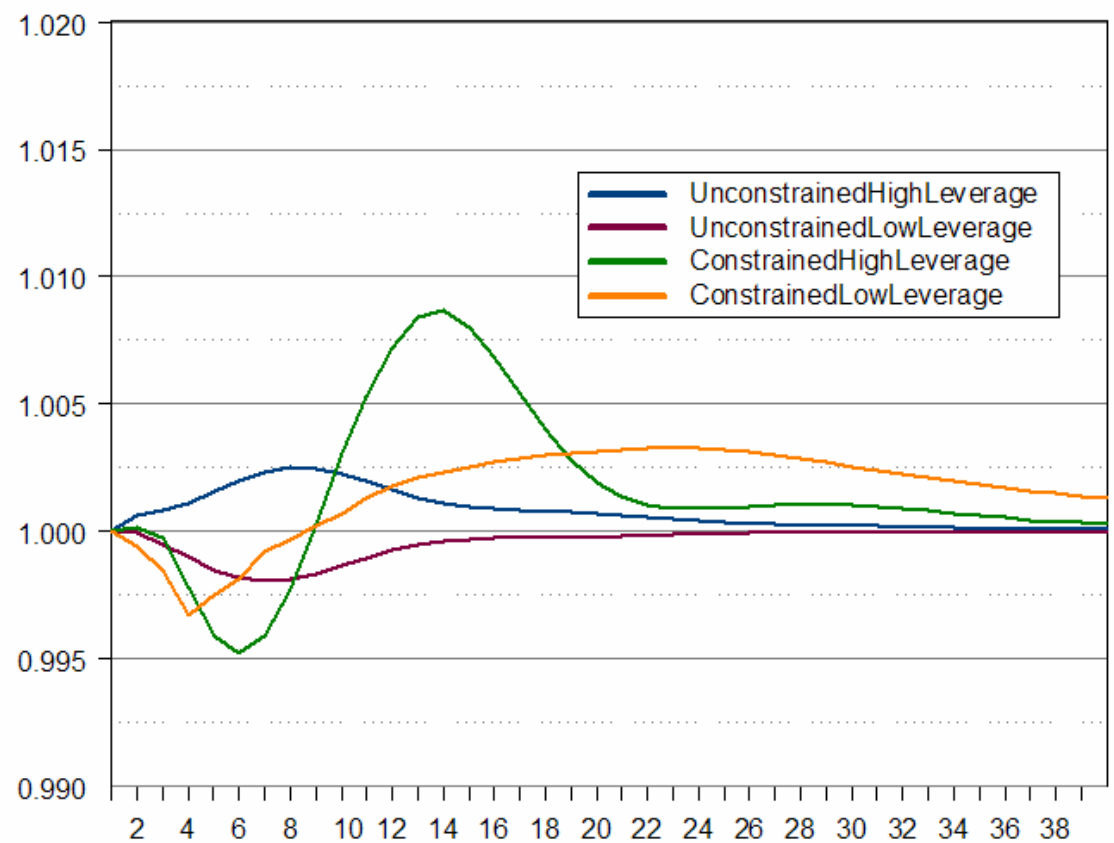

\section{Response of Population Growth to A Negative Volatility Change}

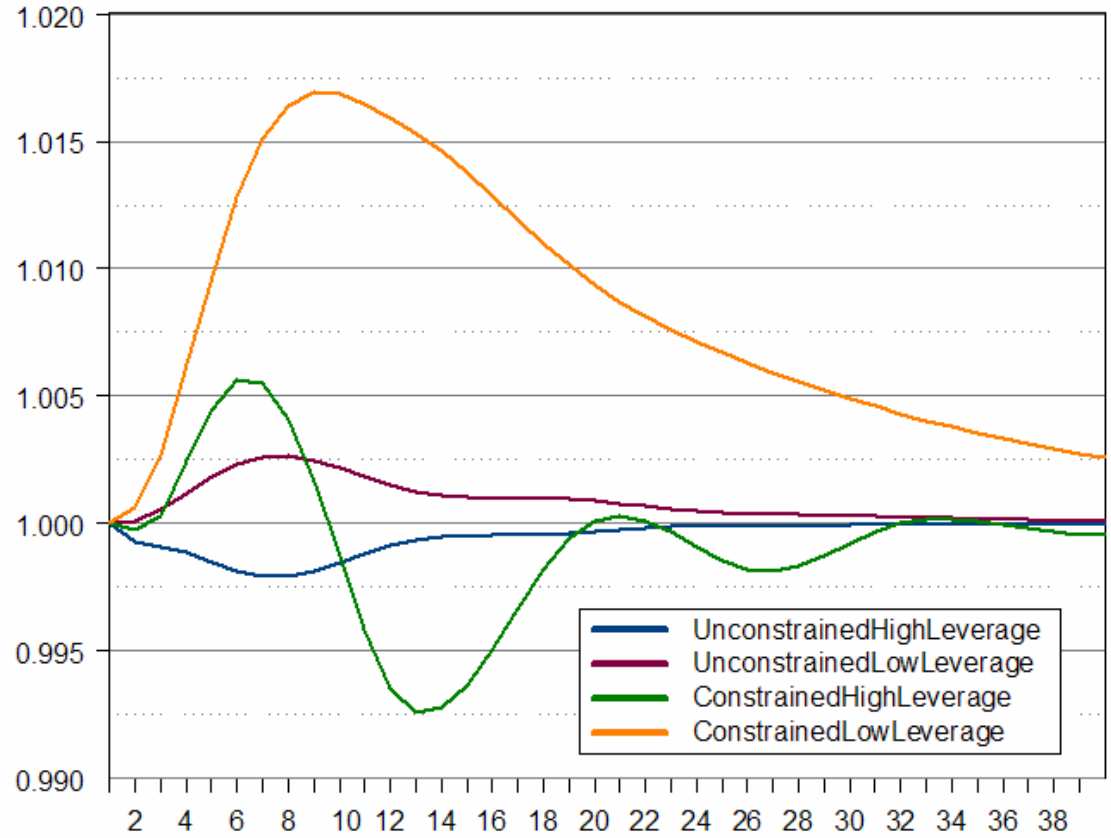

